\title{
Community Health Workers' Role in Solving Health Problems at the Community Level in Bénin and Togo
}

\author{
Panaveyi Vicky Malou Adom ${ }^{1, *}$, Charles Patrick Makoutode ${ }^{2}$, Edgar Marius Ouendo $^{2}$, Takpaya Gnaro ${ }^{1}$, \\ Gado Napo-Koura ${ }^{1}$, Michel Makoutode ${ }^{2}$ \\ ${ }^{1}$ Training Centre for Public Health, Togo \\ ${ }^{2}$ Regional Institute of Public Health, Benin
}

Copyright $\mathrm{O} 2016$ by authors, all rights reserved. Authors agree that this article remains permanently open access under the terms of the Creative Commons Attribution License 4.0 International License

\begin{abstract}
The resolution of health problems at the community level requires firm political will on the part of governments and the effective participation of communities in co-management programs and health activities. The objective of this work is to study the role of Community Health Workers (CHWs) in solving health problems at the community level in Bénin and Togo, from 2009 to 2015. This is an evaluative study of the quasi-experimental type, with its variant "here elsewhere"; it was conducted in six health zones in Bénin and five health districts in Togo, ail randomly chosen from the list of districts and zones within the regions or departmental directions covered. The study involved 385 community health workers and 6150 heads of households. Female heads of households were predominant. The community health workers were predominantly male and their level of education was secondary school and up. Only level of education, marital status and the matrimonial régime of heads of households were not significantly correlated to their level of knowledge in both Bénin and Togo $(p>5 \%)$. The heads of households had an acceptable knowledge of community health workers and their activities, but the subsequently expected favorable behavior towards health remained low. Thus, the role of CHWs in solving health problems was perceived as weak. For a visible impact of the actions of this new class of agents at the community level, a strong political will is needed from the countries in the implementation of World Health Organisation's recommendations on community health.
\end{abstract}

Keywords Community Health Workers, Household, Role, Knowledge, Behavior, Health Issues, Bénin, Togo

\section{Introduction}

The resolution of main public health problems is a major concern in developed as well as developing countries. The majority of communities in the African Region does not have full access to health services and has hardly adopted practices that can improve their health and their survival [1]. This is due to insufficient access to vital interventions, because of lack of relevant information on when and where to seek care, and also because of the alleged poor quality of care and the long distance to the medical centers [2]. The solution to these problems requires a strong political will from governments on the one hand, and an effective participation from communities in co-management of health programs and activities on the other hand. In that connection, the International conference on community health in the African region, held in Addis Ababa, Ethiopia in November 2006, called on ail States to implement a national policy and strategy plans on community health in line with their their national health policies, and to institutionalize community health as the main sector of the national health System [3]. Two years later, in 2008, the Ouagadougou Conference also reasserted the relevance of the involvement, participation and empowerment of the community in the context of health development in order to improve their well-being [4]. Since then, Bénin and Togo who had already been using strategies to bring communities closer to services developed, respectively in 2008 and 2009 , community health reference documents. Efforts were also made in the training of people identified in the villages to provide care and services. They were commonly called community health workers (CHWs). That designation appeared in 1978 at the Aima Ata Declaration (former USSR) which then laid the foundations of primary health care; it was also adopted by the Addis Ababa Declaration on Community Health in the African Region [3,5]. That new class of agents was the interface between health personnel and the community. They were chosen on the basis of certain values (moral, social, professional) expected of them, and were vested with a certain authority and credibility in the field of health by their community. Then, they had to play that role of health workers in order to contribute to the improvement of of the 
health condition of the population.

The objective of this study was to investigate the role played by these agents in solving health problems at the community level in Benin and in Togo, from 2009 to 2015. The research was conducted through the assessment of Community Health Workers' role, the assessment of the knowledge and behavior of households, and by determining the characteristics of the CHWs in relation to knowledge and behavior of households in solving health problems at the community level.

\section{Study Framework}

The study took place in health zones in Benin and in health districts in Togo.

Benin and Togo are West African states located in the Gulf of Guinea. Benin is bordered to the north by the Niger River, to the northwest by Burkina Faso, to the west by Togo, to the east by Nigeria and to the south by the Atlantic Ocean. It covers an area of $114,763 \mathrm{~km}^{2}$. The population in 2014 was estimated at 9,988,068 inhabitants. It has thirty-four (34) health zones grouped into six Regional Health Directions (or Directions Départementales de Santé) [6].

Togo, which spreads over an area of $56,600 \mathrm{~km}^{2}$, had an estimated population of $6,809,900$ in 2014. It is bordered to the north by Burkina Faso, to the south by the Atlantic Ocean, to the east by Benin and to the west by Ghana. The health System is organized into six (06) health regions and the regions are subdivided into forty (40) health districts overall, of which five in Lomé. Each health district is headed by a prefectural health director (or Directeur Préfectoral de la Santé) outside of Lomé, and a district health director (or Directeur de District Sanitaire) in Lomé. [7]

\section{Methodology and Target Population}

This is an evaluative study of the quasi-experimental type in its variant "here elsewhere" which was conducted on a continuous intervention not established by us in Benin and Togo in 2014 and 2015.

The study focused on Community Health Workers (CHWs) and households in six health zones in Benin and five health districts in Togo. It also targeted programs fighting against diseases like Malaria, Tuberculosis, HIV and AIDS, as well as the Extended Immunization Program and the Integrated Management of Childhood Illness at Community level (or Prise en Charge Intégrée des Maladies de l'Enfant au niveau Communautaire).

From the list of districts (in Togo) and zones (in Benin), six health zones and five health districts were randomly selected. The villages inside the districts and zones were selected by cluster sampling technique. They formed clusters and were considered in proportion to their combined number. Drawing inspiration from the sampling technique used by the WHO to evaluate the Extended Immunization Program, we selected 30 clusters per district and zone.
Households were selected in the villages by the route method.

The size of the households sample per district and zone was determined from

$\mathrm{n}=[\mathrm{Za} 2 \times \mathrm{p}$ (i-p) / i2 $]$ with error risk a $=5 \%$ to get a sufficient sample size with a probability of $95 \%$ and $\mathrm{Za}$, the reduced gap corresponding to error risk a equal to 1.96 for an a error risk of $5 \%$. Having no precise information on the proportion $\mathrm{p}$ of the Interventions under Community Directive (or Interventions sous Directive Communautaire), we considered it to be $50 \%$. The size of the calculated sample $(\mathrm{n}=384)$ was multiplied 1.5 times to reduce the cluster effect, and the rounded value obtained was 600 . Thus, in each cluster, 20 households were surveyed.

Community health workers found in a selected village were chosen exhaustively.

The study variables were "knowledge" and "behavior of heads of household" (male or female) for the resolution of health issues at Community level, "characteristics and role of Community Health Workers", and "characteristics of heads of households".

The variables were assessed on the basis of a set of selected criteria that were specified to each variable. For the rating of variables, we complied with Bernoulli's law that encodes the result of a test which allows only two outcomes: 1 for "success", 0 for "failure". [8]

In the study, was considered a success an expected response or when $80 \%$ or more of the respondents gave the expected response, and a failure an unexpected response or when less than $80 \%$ of respondents gave an expected answer. The sum of the scores obtained allowed the assessment of each variable.

The total expected score for the variable "knowledge" was 9, and it was 10 for the variable "behavior". It was 10 for "characteristics of the CHWs" and 12 for "appreciation of their role".

The variable rating scale was adapted from Corlien M. Varkevisser's scale: the satisfaction index was considered good if $[80>$ score $<100 \%$ ]; acceptable if $[60>$ score $<80 \%$ [and bad if [0 $>$ score $<60 \%$ [ [9]. In order to keep two procedures for data analysis, we used two assessment levels that were "good" and "acceptable or bad".

The data were collected by administering questionnaires, the use of documents exploitation slips that had been pre-tested by a team of 10 investigators in each country. They dated back to 2014 and the first half of 2015. The data collected were controlled, then entered and analyzed using the CSPro 5.0 software. The research protocol had been submitted to the ethics committees of both countries and had been agreed upon. The subjects enrolled in the study were informed of the implications of their participation, and reassured that personal information collected would be kept confidential. Informed consent was obtained.

\section{Findings}




\subsection{Characteristics of the Target Population}

\subsubsection{Heads of Households}

The data were collected from 6150 households, 3560 of which in Benin. The majority of the heads of households was in the age range from 15 to $45(80 \%)$, of which $4364(71 \%)$ were unschooled. Female heads of households $(65.5 \%)$ were predominant. Households of six and more represented $51.4 \%$. Almost all the heads of households (5657, which is $92 \%$ ) were married and $53.9 \%$ were cultivators.

\subsubsection{Community Health Workers}

In Bénin, 208 community health workers were enrolled in the study and 177 were enrolled in Togo, which amounts to 385 community health workers. About ail the community health workers were 18 and more. Male community workers $(67.3 \%)$ were predominant. Their education level was secondary school and up.

\subsection{Community Health Workers' Role in Solving Health Problems at the Community Level}

Among the roles, those played by more than $80 \%$ of community health workers in both Bénin and Togo were: home visits (92.3\% in Bénin, $87 \%$ in Togo); participation in meetings at the health facility $(91.8 \%$ in Bénin and $96.6 \%$ in Togo), and implementing recommendations from supervisions (96\% in Bénin, $84 \%$ in Togo). About $93.3 \%$ community health workers in Bénin and $96.6 \%$ in Togo understood the tasks at hand.

In Bénin, the management of cases according to the protocol and cases reviewed for follow ups were a success. Those roles were played respectively by $88 \%$ and $88.5 \%$ in Bénin. The scores were respectively $62.1 \%$ and $29.4 \%$ in Togo.

Less than $80 \%$ community health workers in both countries were able to establish a time line for activities, research cases actively or write monthly activity reports. Only $34.6 \%$ community health workers in Bénin and 24.9\% in Togo showed any consideration for hierarchy.

In case of difficulties, $84.7 \%$ community health workers in Togo and $76 \%$ in Bénin had recourse to health personnel. In Togo, $84.2 \%$ community health workers refer cases to healthcare facilities, against 73.1 in Bénin.

The assessment of community health workers' role was done following some criteria and using scores. Only variables assessing roles with an expected response from at least $80 \%$ community health workers were considered a success. Thus, based on the assessment scale adopted, the CHWs' role in solving a health problem got a score of six in both countries. That score being comprised between [0-60\% [of the total expected score of (12), that is between [0-7[, the community health workers' contribution in solving health problems was rated as poor in both countries.

\subsection{Heads of Households' Knowledge Level about the CHWs and Their Activities}

The diverse assessment criteria of the knowledge level of heads of households about the community health workers (CHWs) and their activities in both countries are presented in the table below.

Of the nine assessment criteria of heads of households' knowledge level about CHWs and their activities, only six (6), that is $67 \%$, were known to more than $80 \%$ households. Thus, referring to the assessment scale adopted, the heads of households' knowledge about CHWs and their activities is acceptable in both Bénin and Togo.

\subsection{Level of Heads of Households' Behavior in Relation to the Different Diseases of Health Programs Considered in This Study}

Among the 6150 heads of households surveyed, 5548 know the community health workers in their community. The number of heads of households who had had one of their family sick during the last three months preceding our investigation was 3748 (67.6\%); among them, 2162 (57.7\%) had consulted a CHW for care.

In Bénin, only in $63.4 \%$ households were there no weeds around the compound, and $72.2 \%$ didn't have any empty containers lying around. In the Togolese households, those score were $38.6 \%$ and $83.7 \%$. The development of a garbage dump in the vicinity of the households was observed in only $56 \%$ households. For $93.5 \%$ households in Benin and $80.1 \%$ in Togo, their less-than-five last children were born in a health facility.

The data on immunization were collected from two sources: the child's vaccination record book and the head of household's statements where the vaccination records were not available or did not exist. In Bénin, in 78.7\% households, ail the children fewer than five took all their vacations according to information gathered from the vaccination record books, against $19.3 \%$ only according to the mothers' statements. The two sources combined gave a score of $96.5 \%$ children with ail vaccinations. Whereas in Togo, only in $48.5 \%$ households did the children get ail their vaccinations, according to information obtained from immunization record book; the score was $42.5 \%$ when based on the heads of households' statements. The combined sources yielded a score of $86.7 \%$. 
Table 1. Distribution of households' according to their level of knowledge of CHWs and their activities in relation to different health programs in Benin and Togo in 2014-2015

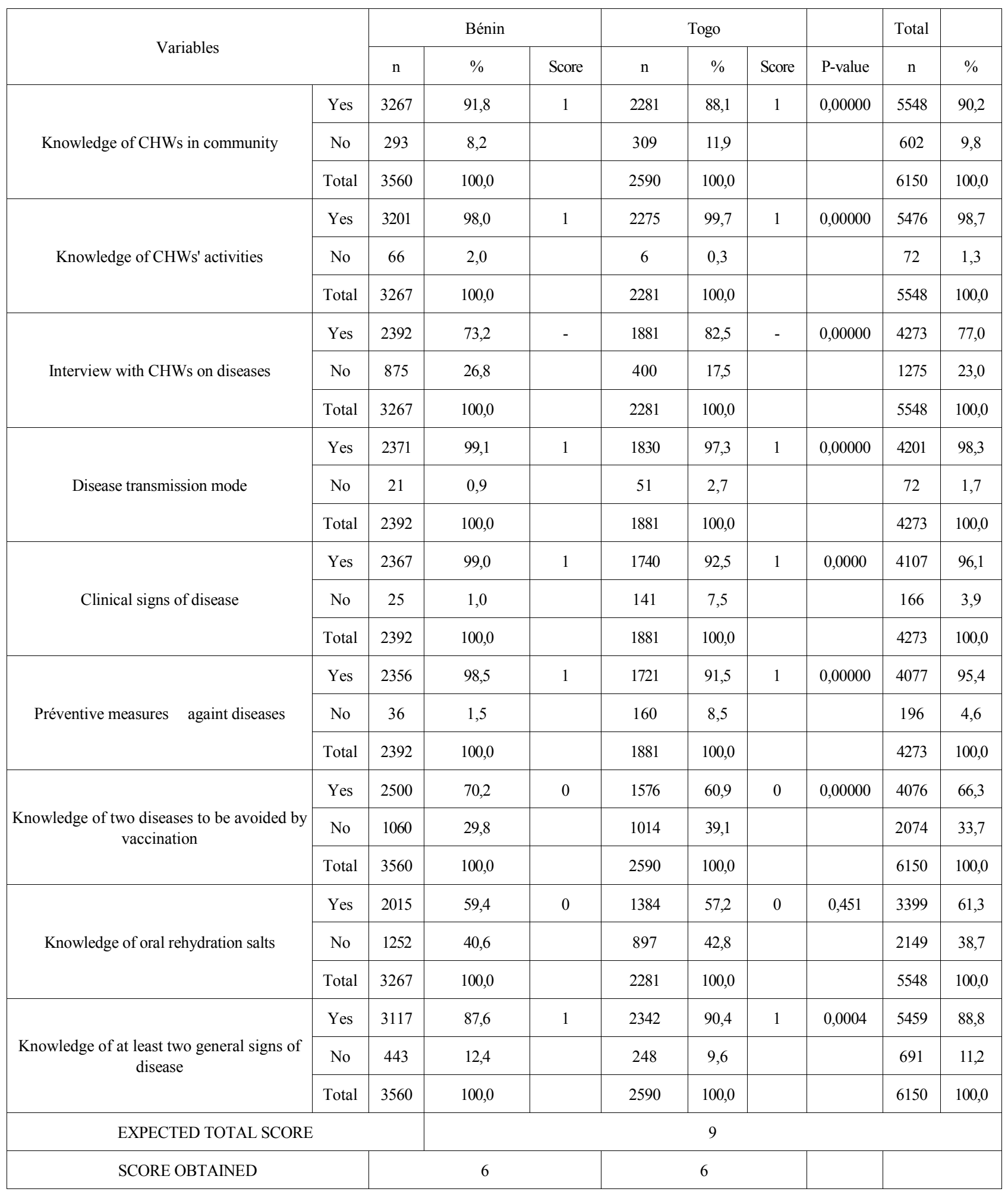


Table 2. Relationship between the level of Knowledge of heads of households and their socio-demographic characteristics in Benin and Togo in 2015

\begin{tabular}{|c|c|c|c|c|c|c|c|c|c|c|c|c|}
\hline & \multicolumn{4}{|c|}{ Togo } & \multicolumn{4}{|c|}{ Bénin } & \multicolumn{4}{|c|}{ Ail together } \\
\hline & $\mathrm{n}=2590$ & $\%$ & $\begin{array}{c}\text { OR } \\
\text { (IC 95\%) }\end{array}$ & $\mathrm{P}$ & $\mathrm{n}=3560$ & $\%$ & OR(IC95\%) & $\mathrm{P}$ & $\mathrm{n}=6150$ & $\%$ & $\begin{array}{c}\text { OR } \\
\text { (IC 95\%) }\end{array}$ & $\mathrm{P}$ \\
\hline $\begin{array}{l}\text { Age of head of } \\
\text { household }\end{array}$ & & & $\begin{array}{c}1,268(1,057 ; \\
1,520)\end{array}$ & 0,010 & & & $\begin{array}{c}1,188 \\
(0,978 ; 1,442)\end{array}$ & 0,083 & & & $\begin{array}{c}1,166(1,022 ; \\
1,329)\end{array}$ & 0,022 \\
\hline $15-45$ years & 1931 & 74,6 & & & 3000 & 84,3 & & & 4931 & 80,2 & & \\
\hline 46 years and up & 659 & 25,4 & & & 560 & 15,7 & & & 1219 & 19,8 & & \\
\hline Sex & & & $\begin{array}{c}1,274(1,077 ; \\
1,507)\end{array}$ & 0,005 & & & $\begin{array}{c}1,416 \\
(1,222-1,640)\end{array}$ & 0,000 & & & $\begin{array}{c}1,367(1,224 \\
1,526)\end{array}$ & 0,000 \\
\hline Female & 1750 & 67,6 & & & 2279 & 64,0 & & & 4029 & 65,5 & & \\
\hline Maie & 840 & 32,4 & & & 1281 & 36,0 & & & 2121 & 34,5 & & \\
\hline Instruction level & & & $\begin{array}{c}0,885(0,750 \\
1,045)\end{array}$ & 0,149 & & & $\begin{array}{c}1,098(0,938 \\
1,286)\end{array}$ & 0,246 & & & $\begin{array}{c}0,969(0,865 \\
1,085)\end{array}$ & 0,584 \\
\hline Unschooled & 1748 & 67,5 & & & 2616 & 73,5 & & & 4364 & 71,0 & & \\
\hline Schooled & 842 & 32,5 & & & 944 & 26,5 & & & 1786 & 29,0 & & \\
\hline Marital Status & & & $\begin{array}{c}1,118(0,864 ; \\
1,446)\end{array}$ & 0,396 & & & $\begin{array}{c}0,854(0,645 \\
1,130) \\
\end{array}$ & 0,270 & & & \begin{tabular}{|c|}
$0,946(0,783 ;$ \\
$1,143)$ \\
\end{tabular} & 0,567 \\
\hline Married & 2320 & 89,6 & & & 3337 & 93,7 & & & 5657 & 92,0 & & \\
\hline Others & 270 & 10,4 & & & 223 & 6,3 & & & 493 & 8,0 & & \\
\hline Marital System & & & $\begin{array}{c}1,766(1,461 \\
2,134)\end{array}$ & 0,000 & & & $\begin{array}{c}0,927 \\
(0,803 ; 1,070)\end{array}$ & 0,301 & & & $\begin{array}{c}1,079(0,966 ; \\
1,206)\end{array}$ & 0,179 \\
\hline Polygamy & 579 & 25,0 & & & 1516 & 45,4 & & & 2095 & 37,0 & & \\
\hline Monogamy & 1741 & 75,0 & & & 1821 & 54,6 & & & 3562 & 63,0 & & \\
\hline Profession & & & $\begin{array}{c}0,576(0,491 ; \\
0,675)\end{array}$ & 0,000 & & & $\begin{array}{c}0,761(0,662 \\
0,875)\end{array}$ & 0,000 & & & $\begin{array}{c}0,701(0,632 ; \\
0,777)\end{array}$ & 0,000 \\
\hline Cultivators & 1539 & 59,4 & & & 1773 & 49,8 & & & 3312 & 53,9 & & \\
\hline Others professions & 1051 & 40,6 & & & 1787 & 50,2 & & & 2838 & 46,1 & & \\
\hline Household size & & & $\begin{array}{c}0,810(0,693 ; \\
0,948)\end{array}$ & 0,009 & & & $\begin{array}{c}1,396(1,215 \\
1,605)\end{array}$ & 0,000 & & & $\begin{array}{c}1,138(1,026 \\
1,262)\end{array}$ & 0,014 \\
\hline Less than 6 & 1429 & 55,2 & & & 1558 & 43,8 & & & 2987 & 48,6 & & \\
\hline 6 and more & 1161 & 44,8 & & & 2002 & 56,2 & & & 3163 & 51,4 & & \\
\hline $\begin{array}{c}\text { Time to go to the } \\
\text { nearest health center }\end{array}$ & & & $\begin{array}{c}1,065(0,906 ; \\
1,251)\end{array}$ & 0,446 & & & $\begin{array}{c}0,576(0,497 \\
0,667)\end{array}$ & 0,000 & & & $\begin{array}{c}0,838(0,756 \\
0,929)\end{array}$ & 0,001 \\
\hline Less than one hour & 1619 & 62,5 & & & 1355 & 38,1 & & & 2974 & 48,4 & & \\
\hline More than one hour & 971 & 37,5 & & & 2205 & 61,9 & & & 3176 & 51,6 & & \\
\hline
\end{tabular}

Of all those assessment criteria, only the birth place of the less-than-five-year-old child in a health facility was met by more than $80 \%$ households in Bénin as well as in Togo.

The assessment of the households' behavior in Bénin and in Togo was carried out following ten criteria. Only the behavior assessment factors which received an expected response with at least $80 \%$ heads of households were considered a success. Thus, only one factor met that requirement; so the score for the assessment of the households' behavior was comprised between [0-60\%] of the total expected score (10), that is between [0-6[. Compared to the chosen assessment scale, the households' behavior towards the CHW' interventions in the different health programs in Bénin and in Togo was rated as poor.

\subsection{Relationship between the Assessment of the Heads of Households' Level of Knowledge and their Socio-demographic Characteristics}

Only level of education, marital status and marital System were not significantly correlated to the level of knowledge of heads of households in Benin and Togo (p>5\%). But level of education and marital status had ORs (0.969 and 0.946) roughly equal to 1 , as well as that of the marital System (Odd Ratio $(\mathrm{OR})=1.079)$.

\section{Discussion}




\subsection{The Quality and Validity of the Study Findings}

The selection of households was probabilistic and that of community health workers (CHWs) was exhaustive. The size of the two samples was representative. The CHWs' mapping files used to compute the number to be surveyed dated back to 2013 in some districts and zones or to 2014 in others. In some health districts and zones, the number of CHWs was found below that registered on documents. The total number of CHWs investigated in both countries was 385. The total planned for was 596. The gap of 211 CHWs could be explained by the fact that three CHWs did not live in the community any more, 48 belonged to 16 villages with difficult access, 22 had moved to other villages for farm work for at least three days or to town for shopping, 12 had abandoned activities and 58 provided only the minimum package while awaiting training to offer the complete package. The remaining 68 represented the CHWs registered on the files but who was nowhere to be found.

As for the heads of households surveyed, they were 6150 instead of 6600 . That difference was due to a lack of access to 16 villages and to the absence of people in some households because of farm work. This constitutes one of the limitations of this study, which is the period chosen for data collection.

The information bias related to the administration tools requesting the translation of the French language into the local language was minimized by the choice of the investigators and the triangulation of data collection techniques. Those investigators who had a link to the community understood and spoke French in addition to at least two languages spoken in the country.

The tools were pre -tested in both countries before they were administered. Beforehand, they had been examined by the ethics committees of Bénin and Togo. Confidentiality was respected when collecting data in both countries. Informed consent was obtained.

\subsection{The Level of Knowledge of Heads of Households}

\section{- Knowledge of heads of households about the CHWs and theirs activities}

The level of knowledge of heads of households about the Community Health Workers (CHWs) and their activities in relation to different health programs in Bénin and Togo was acceptable. The heads of households who knew about the CHWs were $91.8 \%$ in Bénin and $88 \%$ in Togo. That score was $13.7 \%$ lower in an external assessment of the impact of the community management of cases of malaria on child and juvenile mortality in 2012, according to a report from the Cameroon National Institute of Statistics [10]. In our study, respondents were heads of households, both male and female, while the study in Cameroon targeted only women. As for the proportion of heads of households who knew about the CHWs' activities, it was at least as high as $98 \%$. The main reasons for the heads of households to consult CHWs were fever, diarrhea and coughing, just like in the Cameroon study.

\section{- Knowledge of clinical signs, causes and modes of transmission and disease prevention measures}

The heads of households, who consulted a CHW for an illness of a family member in the last three months preceding the survey, had an acceptable knowledge of the disease in question. That knowledge was much more about malaria which was the most cited by households $(68 \%$ in Bénin and Togo to $47.7 \%$ ) as the illness from which suffered most members during the last three months before the investigation. This confirms the first place occupied by malaria amongst the causes of consultation and hospitalization in Bénin and Togo [6,7]. In addition to the important place that disease takes, it is endemic in Bénin as well as in Togo.

We found in our study more CHWs trained in the management of malaria ( $86 \%$ in Bénin to $75.7 \%$ in Togo) and the Integrated Management of Childhood Illnesses (65.9\% in Bénin to $34.4 \%$ in Bénin) than for the other diseases. CHWs trained in Integrated Management of Childhood Illnesses were able to take charge of simple malaria cases and cases of diarrhea and coughing suffered by children under five. This made it easier for them to exchange on those illnesses during their outreach activities. This was confirmed by heads of households who reported that awareness and education topics during home visits by CHWs had focused respectively on malaria $(98.6 \%$ in Bénin and $86.4 \%$ in Togo), diarrhea (28 9\% in Bénin, $26 \%$ in Togo) and coughing (22.4\% in Bénin to $11.8 \%$ in Togo).

Our study has reported that $99 \%$ of heads of households in Bénin and $92.5 \%$ in Togo knew the clinical signs of diseases from which their members had suffered. Those rates were well above the $88 \%$ reported by Malou Adom et al. in a study conducted in Bénin in 2012 on the quality of relays input in the Integrated Management of Childhood Illnesses in the Community, and Kimbi et al. in a study on the knowledge and awareness about malaria prevention in Cameroon in 2014 [11,12]. This difference in proportion might be due to sample size that was larger in our study. However, the knowledge of at least two general signs of disease remained lower than that of simple signs. It was $87 \%$ in Bénin and $90.4 \%$ in Togo.

The causes and transmission modes of diseases that their members had suffered from were known to $99 \%$ of households in Bénin and $97.3 \%$ in Togo, as well as the clinical symptoms ( $99 \%$ in Bénin and $92.5 \%$ in Togo), and preventive measures (98.5\% in Bénin and $91.5 \%$ in Togo). Those results are beyond that of Seck et al. who found in their study in the rural area of Poponguine in Sénégal that $82 \%$ of women had good knowledge of the transmission mode of malaria [13].The difference can be explained by the method used for selecting the target. Only women of childbearing age living in the district of Poponguine for at least one year were included in the study, whereas our study included men and women heads of households. As for York et al. (2015), they reported a lower result of $43 \%$ of villagers who knew 
the cause of onchocerciasis in an exploratory study about the community perception of the factors associated with participation and sustainability of the treatment program with Ivermectin under Community Directive in the south-western Tanzania [14]. As for Stromberg et al., they found that $93 \%$ of the surveyed knew the causes of malaria, in a study on the assessment of knowledge of malaria and the use of treated mosquito nets in Kenya in 2011 [15]. This score is closer to the score found in our study.

\section{- Knowledge and socio-demographic characteristics of household heads}

For all the heads of household surveyed, only level of education, marital status and marital System were not significantly correlated to the level of knowledge of households in Bénin and Togo ( $>5 \%$ ). But the level of education and marital status had OR (0.969 and 0.946) roughly equal to 1 as well as that of the marital System (OR = 1.079). Then there was no relationship between the level of knowledge of heads of household and these factors. That resuit is contrary to that of Ediau et al. in a study on the knowledge and perceptions of communities on the indoor residual spraying for malaria prevention in Soroti district, Uganda in 2013, which found that people with a high level of education (secondary or higher) (OR 4.81, IC 95\% 2.72 to 8.52) were well informed [16]. In that study, the target population came from urban and rural areas, but it was only in rural areas in our study.

From other socio demographic characteristics of households from our study, female gender $((\mathrm{p}=0.0000)$; OR $1.367,95 \%$ CI 1.224 to 1.526$)$, increases the level of knowledge, whereas with farmers $(\mathrm{p}=0.0000$; OR $0.701,95 \%$ CI 0.632 to 0.777 ) this level decreases.

\subsection{The Behavior of Heads of Households}

We found in our study that the level of heads of households' behavior in relation to the interventions by the various health programs conducted by the CHWs is bad in both Bénin and Togo.

Although $98 \%$ of heads of households were aware of the activities carried out by the CHWs, only an average of $77 \%$ had had at least one conversation with him and 57.7\% consulted him for care. The first reason given by households in both countries was their preference for the health structure. They explained this preference by the fact that they thought that the nurse was more competent, or that the CHW did not address the disease in question, or that the CHW had often no medication and always referred, or that the care structure was close to the household. Other reasons given were: lack of $\mathrm{CHW}$, self-medication by street drugs or infusions. In Bénin $14 \%$ of households did not visit the CHWs because he only took care of children. This is not the case in Togo where CHWs had been trained for the therapeutic management of adult patients as well as children suffering from uncomplicated malaria after a Rapid Diagnostic Test (RDT).

Prevention measures were known in $98.5 \%$ of households in Bénin and $91.5 \%$ in Togo. This knowledge was more about malaria, diarrhea and coughing which were the diseases from which household members had most suffered from in Bénin and Togo. However, we found in our study that the heads of households' behavior in relation to preventing factors causing malaria and diarrhea was a failure. In Bénin, it was only around $63.4 \%$ of households that weeds were not observed and $72.2 \%$ of compounds who did not have used empty containers lying about. As for households in Togo, in 38.6\% there were no grasses around concessions but the rate was much higher than $83.7 \%$ for the lack of used containers or empty cans. The difference in proportion between the two countries regarding the lack of weeds around the concessions and the lack of used containers or empty cans was highly significant $(\mathrm{P}=0.0000)$.

Those findings are similar to those by Delacollette et al. who, in a study on the use of CHWs for malaria control in 1996, found that while most people knew that mosquito nets were efficient in the prevention of malaria, the use of the nets was still very low [17].

It is important to note that in our study, the proportion of heads of households (93.5\% in Bénin and $80.1 \%$ in Togo) who said that the birth of their last child under five years took place in a health facility was respectively higher than $87 \%$ reported by Enquêtes Démographiques de Santé or Demography Enquiries for Health in 2012 in Bénin and then $73 \%$ reported by EDS in 2013 [18, 19]. In their book of specifications, the Community Health Workers listed the sensitization of women about the benefits of giving birth in a health facility.

The immunization data were collected from two sources: the child's immunization record book and the Declaration of the household's head when the book was not available or did not exist. Our study revealed that in Bénin about 8 out of 10 children under 5 years $(78.7 \%)$ were fully vaccinated according to information obtained from the immunization record book and only $19.3 \%$ as reported by the mother. When combining the two sources, $96.5 \%$ were fully immunized. In Togo, in the meanwhile, only 5 out of 10 children under 5 years $(48.5 \%)$ were fully immunized according to information obtained from the immunization records and $42.5 \%$ as reported by household heads. Information from both sources gave a rate of $86.7 \%$, lower than that obtained in Bénin. The results obtained in both countries by the Demography and Health Surveys are much lower than our study's numbers. In Bénin about 4 children in 10 aged 12-23 months (39\%) were fully vaccinated according to both sources and in Togo this rate was $61 \%$ for the same target $[18,19]$. That difference can be explained by the target of our study (children under five) that is wider, which might have allowed a catch missed opportunities especially during vaccination campaigns. Kawakatsu et al. confirmed this hypothesis in a study on the identification of individual and community determinants of complete vaccination coverage among children aged 12-59 months in Nyanza Province, Kenya in 2015 [20]. 


\subsection{The Role of Community Health Agents}

As the main actor in the implementation of the action plan at community level, the Community Health Worker plays an interface role between individuals, families and health professionals.

The CHW's activities may for example relate to the promotion of essential family practices, prevention and support of community management of priority affections, the implementation of the health promoting devices [21, 22].

For a better implementation of activities, the CHW should understand the meaning of his task. Thus, in our study, at least nine out of ten CHWs in both countries, understood the meaning of their work. This might have had an impact on the level of knowledge of heads of household, which was acceptable in both countries.

It is clear from our study that only the CHWs who played an acceptable role were able to give heads of households a good level of knowledge that not reflected in their behaviors in family practices for disease prevention, unfortunately. That confirms this World Health Organization's assertion in his book, Communication for behavioral impact to roll back malaria, "We realize very quickly that we can easily achieve the goal of raising awareness, information, the education and persuasion of people about what needs to be done, but we realize that it is another matter to have a behavioral response"[23]. The technique used by the CHWs for information, education and communication can be the key factors of the level of heads of households' behavior. To enable this change of heads of households' behavior desired in the implementation of Community-Directed Intervention (CDI) in Bénin and in Togo, CHWs could adopt the approach based on the focus on the human that allows contact with the person and his emotions, as described by Groulx and Chapuis in their book, Changing health behavior through marketing-inspired methods, 2004 [24].

The proportion of CHWs taking care of patients according to the protocol was assessed by information gathered from consultations registers. That proportion was significantly higher in Bénin $(88 \%)$ than in Togo $(62.1 \%)\left(\mathrm{p}=10^{110}\right)$. Application of the recommendations of supervision and participation at meetings of the healthcare facility by CHWs were respectively $96 \%$ and $91.8 \%$ in Bénin and $84 \%$ and $96.6 \%$ in Togo can improve their competence in the management of cases. The meetings are strategies often used by the facilitator of the NGO to collect progress reports and discuss with CHWs on their role. Malou Adom et al. reported a rate of (97.4\%) in 2012 in Bénin in a study that took into account only the CHWs of Integrated Management of Child Illnesses in the Community [11].

Home visits are an important activity that brings $\mathrm{CHWs}$ to the household members, and that gives them the opportunity to pass on messages about family health-promoting practices. In Bénin (92.3\%) and Togo (87\%), about nine in ten CHWs achieved this activity during 2014 and the first half of 2015 . This may also explain the acquisition of knowledge to an acceptable level of household heads. Vouking et al. also reached in an evaluation of the participation of community health workers in the early diagnosis and treatment of Buruli ulcer Ngoantet, Cameroonin 2013 to demonstrate the role played by the CHWs through home visits [25]. This observation was also made by Pati et al. in an intervention where community health workers through home visits were successful in increasing infants' immunization rates [26].

The CHWs in Togo $(84.7 \%)$ are more aware of their limitations and resort to the use of health workers in the event of difficulties, as those of Bénin (76\%); but this difference was not significant ( $p=0.043$ ). It is the same for the reference case by CHWs with $73.1 \%$ in Bénin and $84.2 \%$ in Togo. This rate of $95 \%$ reported by the study conducted by Vouking et al. in Cameroon in 2013 is higher than those found in our study [25]. This difference is explained by the activities in question. Our study involved several diseases while that by Vouking et al. was only centered on Buruli ulcer which is a disease for which the treatment cannot be made by the CHWs. That limitation is also the leading cause of reference in our study in addition to the frequent drugs shortages that $\mathrm{CHW}$ sace.

\section{Conclusions}

This study made it possible to assess the role played by community health workers (CHWs) in solving health problems in communities in Bénin and Togo. The CHWs understood the meaning of their tasks and succeeded in giving to heads of household's acceptable knowledge on different diseases; however, change of behavior conducive to a good health remained weak. Although they were trained before the beginning of their activities, the community health workers' job could have a better impact on the community members' health if their performance could stay permanently high.

\section{Conflicts of Interest}

The authors declare no conflict of interest.

\section{Acknowledgements}

The authors thank the participants in the study.

\section{REFERENCES}

[1] OMS/AFRO. Framework for the design community pilot integrated interventions to promote health and to support the WHO's priority programs, pp. 42, 2009.

[2] World Health Organization, World Health Statistics, pp. 172, 2013.

[3] WHO / UNICEF / UNAIDS. Addis Ababa Declaration on 
Community Health in the African Region. 2006

[4] World Health Organization. Summary of country experiences in the revitalization of primary health care. In WHO/AFR/PHC/08/2 Ouagadougou-BURKINA-FASO, 2008.

[5] Marchais M-A. Reference Framework Community Health Workers, Doctors of the World, pp55, 2009. Bénin

[6] Ministry of health, health statistics yearbook 2O14.(SNIGS-MS) pp. 162, Cotonou; 2015

[7] Ministry of health, Key Health Indicators Togo 2014 (DGPIS-MS), pp.69, 2015.

[8] T A: Statistique épidémiologique, epidemiological Statistics 3ème édition Maloine, 2011.

[9] Centre WHOIDR. Designing and conducting health Systems research projects. KIT/IDRC/AFRO/OMS; 2003.

[10] National Institute of Statistics of Cameroon. External evaluation on the impact of community ownership of malaria on child mortality in 2012. Yaoundé (Cameroun), pp. 66.2012 .

[11] MalouAdom PV, Ouendo EM, Salami L, Napo- Koura G, Makoutodé M. Quality of the contribution of community volunteers in Bénin community-based IMCI. Santépublique, volume $26 / \mathrm{N}^{\circ} 2: 241-248.2014$.

[12] Kimbi HK, S. B. Nkesa, J. L. Ndamukong-Nyanga, I. U. Sumbele, J. Atashili and M. B. Atanga. Knowledge and perceptions towards malaria prevention among vulnerable groups in the Buea Health District, Cameroon. In BMC Public Health vol. 27. pp.883. 2014.

[13] Seck I FI, Faye A, Ba O, Tal-Dia A. Malaria knowledge, attitudes and practices among women living in the rural area of poponguine, SénégalMed Trop, 68:629-633,2008.

[14] York KJ K1, Mrisho M, Berry DM, Schmidt E. Factors affecting community participation in the CDU program in Morogoro, Tanzania. JNursScholarsh, 47:96-104. 2015.

[15] Stromberg DG JF, J Hruschka, A. Tomedi and M Mwanthi. A community health worker program for the prevention of malaria in eastern Kenya. Education Health (Abingdon),
$24: 474,2011$.

[16] Ediau M BJ, Tumwesigye NM, MatovuJK, Machingaidze S, Okui O, Wanyenze RK, Waiswa P. Community knowledge and perceptions about indoor residual spraying for malaria prevention in Soroti district, Uganda: a cross-sectional study. MalarJ, 12:170, 2013.

[17] Delacollette C VdSP, Molima K: Using community health workers for malaria control: experience in Zaire. Bull World Health Organ, 74:423-430, 1996.

[18] National Institute of statistics and economy analysis (Bénin). Demography and health survey 2011-2012. Calverton, Maryland, USA: INSAE etICF International, pp 513, 2013.

[19] Gênerai Directorate of Statistics and National Accounts, Demography and health survey Togo 2013 (EDST-III) Preliminary report, pp. 40, 2014.

[20] Kawakatsu Y TJ, Ogawa K, Ogendo K, Honda S. : Effects of three interventions and determinants of full vaccination among children aged 12-59 months in Nyanza province, Kenya. Public health, 129 (11):1530:1538, 2015.

[21] Ministry of Health Bénin. National guidelines for health promotion at the community level pp. 31. Cotonou, 2010.

[22] Ministry of Health Togo. National community-based interventions Policy, Lomé, 2015.

[23] World Health Organization, Communication for Behavioural Impact and Roll Back Malaria, pp. 35; 2002.

[24] Groulx S CP, (http://extranet.santemonteregie.qc.ca/userfiles/ file/sante-pu

blique/promotion-prevention/N3-PCPChangerComportemen tsSant\%C3\%A9M\%C3\%A9thodesMarketing.pdf.ed.; 2004. Consulted April 15, 2016;

[25] VoukingMZ, Takougang I, Mbam LM, Mbuagbaw L, Tadenfok CN, CV. T. The contribution of community health workers to the control of Buruli ulcer in the Ngoantet area, Cameroon. Pan AfrMed J, 16:63, 2013.

[26] Pati S LK, Wong AT, Huang J, Yang J. An enriched medical home intervention using community health workers improves adherence to immunization schedules. Vaccine 2015. 